The object of Dr. Dawkins' little book is to assess the influence of the new development on post-operative mortality and morbidity. For this purpose an analysis has been made of no less than 16,000 general and local anæsthesias used with and without various types of basal narcosis.

The collection and tabulation of such a vast mass of statistics have obviously entailed an immense amount of work and Dr. Dawkins' conclusions should be read and taken to heart by all engaged in surgery and anæsthesia. It is impossible even to summarize his results here, but several important facts emerge. One is that, as so many previous observers have found, local analgesia, per se, does not diminish pulmonary complications. The chief point that the author makes, however, is that the incidence of these complications is greatly increased by the use of routine and injudicious basal narcosis.

An unbiased survey of this subject has been long overdue and one cannot escape the conclusion that if basal narcosis is to be employed, it must be in the sole charge of a really experienced anæsthetist who has considered the patient and operation from every relevant angle.

A list of 90 references is found at the end of the book.

\section{FOOD AND THE PRINCIPLES OF DIETETICS.}

\section{(Eighth Edition)}

By Dr. Robt. Hutchison and Prof. V. H.

Mottram. Messrs. Edward Arnold \& Co. 1936. Price 21/-.

Although this is the eighth edition of this well-known book we feel sure that there never was a time when it would be not only more welcome but also more useful. Since the last edition the world has become diet or food conscious, and hence there is an. urgent need that reliable and sound information on the part which food plays in health and disease should be available. The scientific, and unfortunately also unscientific, work which has been done during the last fifty years on the general subject of nutrition, on the analysis of different foods, on the changes which these undergo during the process of cooking or other treatment, and on their effects on the physiological and pathological processes is enormous. In this volume Dr. Hutchison and his collaborator Prof. Mottram have brought together the fruit of this labour, and what is equally if not more important, they have submitted the available information to a scientific and clinical scrutiny so that a most sound, dependable and, it may also be mentioned, readable work is the result. There are many illustrations and tables of analyses and copious references to original sources throughout the text, and a very full index which renders the work in addition a valuable book of ready reference.

\section{A SYSTEM OF CLINICAL MEDICINE.}

\section{(Tenth Edition.)}

Edited by Agnes Savill, M.D. and E. C. WARner, M.D. Messrs. Edward Arnold \& Co. 1936. Price 28/-.

Any book which has passed through ten editions has demonstrated conclusively that it supplies a demand and that this has been the case with Savill's System of Clinical Medicine is not cause for surprise. Indeed, it is astonishing that it has no competitors for the plan of the book is an admirable method of arousing the student's interest in his subject and thus of imparting knowledge. Most text-books confine themselves either to methods of physical diagnosis or to a more or less academic discussion of the different diseases grouped according to ætiology or organ or part of body attacked. In Savill's Medicine, however, the introduction is by symptom and from this the student is conducted through the necessary examination to a consideration of the possible diseased conditions, the ætiology, life history and treatment being finally discussed. It is in this way, we are convinced, that the facts are most firmly impressed on the memory of the reader.

Each succeeding edition has been more comprehensive than its predecessor and in this, the tenth, in which Dr. Agnes Savill (the widow of the original author) has the assistance as co-editor of Dr. E. C. Warner and the help of a group of well-known 